\title{
A Novel Protection Algorithm for Phase to Phase Faults in Double Circuit Transmission Lines
}

\author{
A Naresh Kumar, Ch Sanjay, M Chakravarthy
}

\begin{abstract}
The selection of robots used for industry purpose is a crucial practice where various parameters have to be considered during appropriate selection process. The decision strategy of robot selection has a potential research direction to justify the necessity of industrial needs. We have compared three different mathematical models and selected the best method for choosing the a targeted application. In addition to the mathematical methodologies applied here, the performance characteristics for selecting the robot is examined by assessment of statistical errors namely Mean Square Error (MSE), Root Mean Square Error (RMSE), and R-Squared Error (RSE).
\end{abstract}

Keywords: Robot selection, PLSR, FNN, PCR, Selection Framework, Robot parameters.

\section{INTRODUCTION}

Recent days have witnessed growing energy system demand. To facilitate increase in a demand of electrical energy, it is essential to enhance the power handling capacity of existing line. Owing to a constraint of infrastructure, land availability \& various environmental issues, multiple phase line is a choice scheme for increasing electrical power handling capacity of power line. Nowadays, the multiple phase transmission line has appeared as the possible transmission an alternative to attain efficient usage of a rights of way \& improved power transmission capacity to reach rising power demand. PT is the potential choice among the multiple phase transmission lines, for transferring extra electrical energy with the existing configuration of a PT lines.

Preliminary studies on the designing and implementation have discussed the feasibility of PT line [1-9]. To maintain the steadiness of the transmission network under all running situations, it is required to build up a sufficient protection system which protects network by isolating part of power line only that is faulted, while leaving as more of the system as possible a still in action. Thus, protection systems must be applying practical algorithm in clearing faults. Therefore, it is vital to make up a quick reliable $\&$ a complete protection network for different shunt fault cases. There are 57 combination of possible faults in a PT line, which is additional as compared to a 11 combinations in a 3 phase transmission line. Thus, the complexities of protection system for a PT lines is additional as compared to 3-phase power line. A different fault normally to occur on a PT line has been discussed in various papers [10-12] using unsymmetrical

Revised Manuscript Received on October 15, 2019.

A Naresh kumar, EEE Department at Institute of Aeronautical Engineering, India.

Ch Sanjay, Department of ME at GITAM University, India.

M Chakravarthy, Department of EEE at Vasavi College of Engineering, India.. components, symmetrical components \& phase coordinates scheme.

In Ref [13, 14], different classification algorithms for shunt faults of line have been demonstrated using the voltages and currents on one end. Some protection techniques use only the faulty currents $[15,16]$. Shunt fault classification as an input of fundamental component of currents in transmission line has been widely studied [17]. As reported in [18, 19, 20, 21] many fault classification approaches were discussed mainly for PT lines. Some of the above-mentioned methodologies did not provide the classification of shunt fault in PT line, which took up to half cycle. Fault classification using k-NN in three phase circuit lines are explained in [22]. The purpose of proposed paper is to design an efficient phase to phase fault classification methodology in PT line considering k-NN and fundamental frequency component of currents. Indeed, the core idea of this work is to improve accuracy of classification. Thus, an improved k-NN method for fault classification in PT line is proposed in this paper.

We organized the rest of our paper as follows. Section II demonstrates the PT line configuration, modeling and simulation of phase-phase faults. Section III illustrates the k-NN approach for classifying phase-phase faults. Section IV explains the simulation results for classifying phase to phase fault cases. Our conclusion is presented in Section V.

\section{SIMULATION OF PT TRANSMISSION LINE}

A one line diagram of PT module is seen in Fig. 1. The module consists of $138 \mathrm{kV}, 50 \mathrm{~Hz}$ line of length $68 \mathrm{~km}$. The line is supply from two sources at both receiving end and source end with both loads of $100 \mathrm{MVAR}$ and $250 \mathrm{MW}$ at receiving side. The $\mathrm{X} / \mathrm{R}$ ratio \& their short-circuit capability of sources at two the ends are 10 and 1250 MVA, respectively. Basic network description \& configuration of data of PT line used in the presented work are illustrated in Table. 1. The PT module is implemented and simulated using a Simulink \& Simpowersystems toolboxes of MATLAB. The 6-phase current signal waveform of corresponding transmission line phases during phase-phase a \& b fault in phases " $a$ and b" at $40 \mathrm{~km}$ from the source point and at fault inception angle $90^{\circ}$ are shown in Figure 2. The recorded instantaneous six current inputs were sampled at $1200 \mathrm{~Hz}$ sampling frequency and then processed by a simple 2 nd-order Butter worth filter with cut-off frequency of $480 \mathrm{~Hz}$. 1 full cycle DFT has been given herein to exercise the time series current $\&$ the fundamental component of six phase current waveforms has been estimated using DFT block of MATLAB ( $)$ software. The k-NN approach employs the fundamental component of 6-phase currents at one terminal of line only.

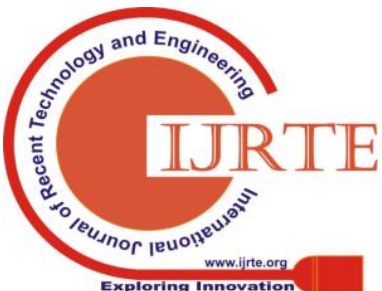




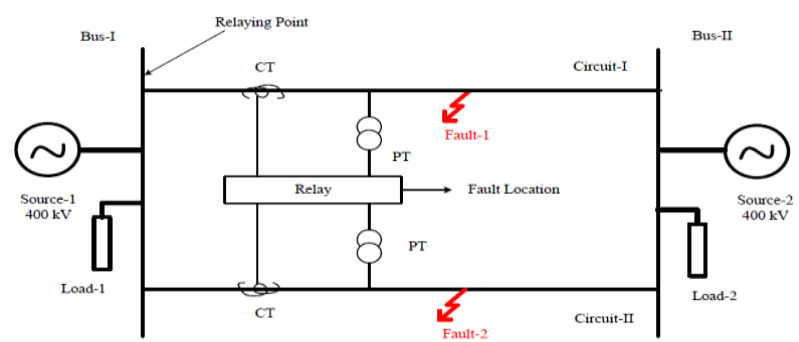

Figure.1. Power System Network considered

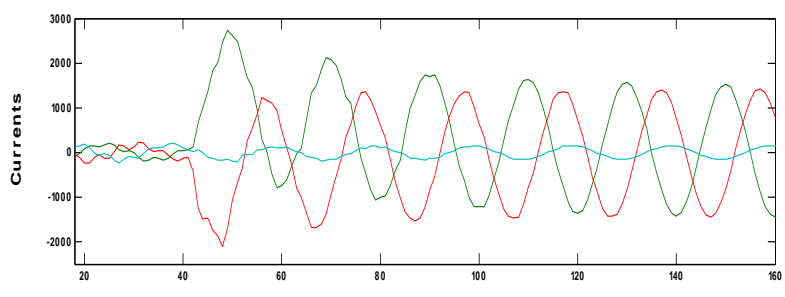

Time

Fig.2. PT currents during of phase to phase fault

Table.1. Basic system description data

\begin{tabular}{|l|l|}
\hline Parameter & Nominal Values \\
\hline Base Voltage (V) & $138 \mathrm{kV}$ \\
\hline Base Power (P) & $100000 \mathrm{KVA}$ \\
\hline Frequency (f) & $50 \mathrm{~Hz}$ \\
\hline Earth Resistivity & $110 \Omega-\mathrm{m}$ \\
\hline Line Length (L) & $68 \mathrm{~km}$ \\
\hline Short Circuit Capability & 1200 \\
\hline X/R Ratio of the Source & 10 \\
\hline Load at Bus & $100000 \mathrm{~W}$ \\
\cline { 2 - 2 } & $100000 \mathrm{VAR}$ \\
\hline
\end{tabular}

\section{DESIGNING OF K-NN NETWORK}

The k-NN fault classification technique is designed for classifying various types of phase-phase faults. K-NN system consists of 2 different k-NN systems: k-NN-1 and k-NN-2. The k-NN-1 system is considered to identify the faulted phases, whereas k-NN-2 identifies whether the of phase to phase fault involving ground or not. The training pattern employed for modeling the k-NN-1 systems are fundamental component of six phase currents. Corresponding output target for different faulty phases are assigned as No fault -0 and faulty phase- 1 . The $\mathrm{k}-\mathrm{NN}-2$ module is considered by choosing zero (0) sequence component of currents as inputs. From the zero (0) sequence component, 5 post-faults samples are obtained from each condition. Corresponding output targets are assigned as " 0 " for the no-fault, " 1 "for phase to phase faults. The training network performance is validated by changing $\mathrm{k}$ for both $\mathrm{k}-\mathrm{NN}-1$ and $\mathrm{k}-\mathrm{NN}-2$ systems as listed in Table 2 and 3, respectively. Highest training accuracy for $\mathrm{k}-\mathrm{NN}-1$ and $\mathrm{k}-\mathrm{NN}-2$ system is obtained with $\mathrm{k}=2$, thus $\mathrm{k}=2$ is selected for $\mathrm{k}-\mathrm{NN}-1$ and $\mathrm{k}-\mathrm{NN}-2$ systems as their nearest neighbors.

\section{SIMULATION RESULTS}

Testing is vital to verify the performance of k-NN based fault classifier. The proposed $\mathrm{k}-\mathrm{NN}$ based fault classifier is verifiedd using test data chosing all types of shunt fault with change in a fault distance location from 1-67 km and FIA between $0-360^{\circ}$. Total 57 fault cases are simulated and tested. After checking the proposed k-NN based phase to phase fault classifier, it has been determined that it is able to correctly classified all possible types of phase to phase faults i.e. an accuracy of $100 \%$. The accuracy is obtained using a equation (1) in faulty classification.

\section{Accuracy $=$ \\ $\frac{\text { Number of testing samples correcly classified }}{\text { No }} \times 100$.. Number of testing samples}

Table. 2. Test results of k-NN classifier for variety of FIA

\begin{tabular}{|c|l|c|r|r|r|r|r|}
\hline \multirow{2}{*}{ Fault type } & \multirow{2}{*}{ FIA } & \multicolumn{6}{|c|}{ Output of k-NN-based fault classifier } \\
\cline { 3 - 8 } & & AI & \multicolumn{1}{|c|}{ BI } & CI & AII & BII & CII \\
\hline AIICII & $30^{\circ}$ & 0 & 0 & 0 & 1 & 0 & 1.01 \\
\hline AIBICI & $50^{\circ}$ & 0.99 & 1 & 1 & 0 & 0 & 0 \\
\hline AIIBII & $120^{\circ}$ & 0 & 0 & 0 & 1 & 1 & 0 \\
\hline AIBICI & $160^{\circ}$ & 0.99 & 1 & 1 & 0.02 & 0.02 & 0 \\
\hline AIICII & $330^{\circ}$ & 0.01 & 0.01 & 0.04 & 0.01 & 0.94 & 1 \\
\hline AIICII & $20^{\circ}$ & 0 & 0 & 0 & 0.99 & 0 & 0.99 \\
\hline AIIBIICII & $80^{\circ}$ & 0 & 0 & 0 & 1 & 1 & 0.99 \\
\hline AIIBIICII & $150^{\circ}$ & 0 & 0.02 & 0 & 1 & 0.99 & 1 \\
\hline AICI & $230^{\circ}$ & 0.98 & 0 & 0.99 & 0 & 0 & 0 \\
\hline AIIBIICII & $320^{\circ}$ & 0.01 & 0.01 & 0 & 0.99 & 1.01 & 1 \\
\hline
\end{tabular}

Table. 3. Test results of k-NN classifier for variety of fault locations

\begin{tabular}{|c|c|r|r|r|r|r|r|}
\hline \multirow{2}{*}{ Fault type } & \multirow{2}{*}{$\begin{array}{l}\text { L in } \\
\mathbf{k m}\end{array}$} & \multicolumn{6}{|c|}{ Output of k-NN-based fault } \\
& & AI & BI & CI & AII & BII & CII \\
\hline AIICII & 2 & 0 & 0 & 0 & 1.01 & 0 & 1.02 \\
\hline AIBICI & 6 & 0.98 & 0.99 & 1 & 0 & 0 & 0 \\
\hline AIIBII & 13 & 0 & 0 & 0 & 1 & 1 & 0 \\
\hline AIBICI & 24 & 0.99 & 1 & 1 & 0.01 & 0 & 0 \\
\hline AIICII & 37 & 0.02 & 0.01 & 0 & 0.01 & 1 & 1 \\
\hline AIICII & 46 & 0 & 0 & 0 & 1 & 0 & 0.99 \\
\hline AIIBIICII & 42 & 0 & 0 & 0 & 1 & 1 & 0.99 \\
\hline AIIBIICII & 51 & 0 & 0.02 & 0 & 1 & 0.99 & 1 \\
\hline
\end{tabular}




\begin{tabular}{|c|c|c|c|c|c|c|c|}
\hline AICI & 65 & 0.99 & 0 & 0.98 & 0 & 0 & 0 \\
\hline AIIBIICII & 88 & 0.01 & 0.01 & 0 & 0.99 & 1.01 & 1 \\
\hline AIBI & 98 & 0.99 & 0.98 & 0 & 0 & 0 & 0 \\
\hline
\end{tabular}

\section{CONCLUSION}

This article presents an accurate approach for classification of phase to phase faults in PT line based k-NN. Various types of shunt fault, under changing fault cases such as location of fault from source terminal $(1-67 \mathrm{~km})$ \& FIA $\left(0-360^{\circ}\right)$ have been investigated. The approach adopts the fundamental component of currents of the line at one end line. The performance of k-NN approach has been validated by number of the tests. The offline test results confirm the suitability of proposed k-NN approach.

\section{REFERENCES}

1. Kang, N., Liao, Y.: Double-circuit transmission-line fault location utilizing synchronized current phasors. IEEE Transactions on Power Delivery. 28(2), 1040-1047, (2013)

2. Elkalashy, N., Kawady, T., Khater, W., Taalab, A.: Unsynchronized fault-location technique for double-circuit transmission systems independent of line parameters. IEEE Transactions on Power Delivery. 31(4), 1591-1600, (2016)

3. Apostolopoulos, C., Korres, G.: A novel fault-location algorithm for double-circuit transmission lines without utilizing line parameters. IEEE Transactions on Power Delivery. 26(3), 1467-1478, (2011)

4. Naresh, A., Sanjay, Ch., Chakravarthy, M.: Fuzzy inference system-based solution to locate the cross-country faults in parallel transmission line. The International Journal of Electrical Engineering \& Education. (2019) https://doi.org/10.1177/0020720919830905

5. Barnes H.C, Barthold L. O, High Phase Order Transmission, Electra, 24, (1973),139-153.

6. Stewart J.R, Wilson D.D. High Phase Order Transmission-a Feasibility Analysis Part-I Steady State Considerations, IEEE Transactions Power Apparatus and Systems, 97, No.6, (1978), 2300-2307.

7. Stewart JR, Grant IS, High Phase Order - Ready for Application, IEEE Transactions on Power Apparatus and Systems, 101, No. 6, (1982), 1757-1764.

8. Tiaras N, Singh LP, Mathematical Modelling and Analysis of Multi Phase Systems, IEEE Transactions on Power Apparatus and Systems, 101, No.6, (1982), 1784-1793.

9. Stewart JR, Kallaur E, Grant IS, Economics of EHV High Phase Order Transmission, IEEE Transactions on Power Apparatus and Systems, 103, No.6, (1984), 3386-3392.

10. Tiwari SN, Singh GK, Multi-Phase Transmission Research-A Survey, Electrical Power System Research, 24, (1992), 207-215.

11. Bhatt NB, Venkata SS, Guyker WC, Booth WH, Six-Phase (Multi-Phase) Power Transmission System: Fault Analysis, IEEE Transactions on Power Apparatus and Systems, 96, No. 3, (1977), $758-767$.

12. Venkata SS, Guyker WC, Kondragunta J, Saini NK, Stanek EK, 138-kV, Six Phase Transmission System: Fault Analysis, IEEE Transaction on Power Apparatus and systems, 101, No. 5, (1982), 1203-1216.

13. Onogi Y, Isaka K, Chiba A, Okumoto Y, A Method of Suppressing Fault Currents and Improving the Ground Level Electric Field in a Novel Six-Phase Transmission System, IEEE Transactions on Power Apparatus and Systems, 102, No. 4, (1983), 870-879.

14. Sami Ekici, Support Vector Machines for Classification and Locating Faults on Transmission Lines, Applied Soft Computing, 12, No. 6, (2012), 1650-1658.

15. Soumyadip Jana, Sudipta Nath, Aritra Dasgupta, Transmission Line Fault Classification Based on Wavelet Entropy and Neural Network, International Journal of Electrical Engineering and Technology, 3, No. 2, (2012).

16. Simi P Valsan, K Shanti Swarup, High Speed Fault Classification in Power Lines: Theory and FPGA Based Implementation, IEEE Trans. Industrial Electronics, 6, No.5, (2009), 1793-1800.
17. L.N. Tripaty, P.K. Dash, S.R. Samantary, A New Cross- Differential Protection Scheme for Parallel Transmission Lines Including UPFC, IEEE Trans. Power Delivery, 29, No.4, (2014), 1822-1830.

18. Jain A, Thoke. A. S, Patel R.N, Modi P.K, Classification and Location of Single Line to Ground Faults in Double Circuit Transmission Lines using Artificial Neural Networks, International Journal of Power and Energy Conversion, 2, No. 2, (2010), 109-125.

19. Ebha Koley, Khushaboo Verma, Subhojit Ghosh, An Improved Fault Detection Classification and Fault Location Scheme Based on Wavelet Transform and Artificial Neural Networks for Six Phase Transmission Line using Single End Data only, Springer Plus, (2015).

20. A. Naresh Kumar, Chakravarthy M, Simultaneous Fault Classification and Localization Scheme in Six Phase Transmission Line using Artificial Neural Networks, Journal of Advanced Research in Dynamical \& Control Systems, 10, No. 3, (2018), 342-349.

21. Ebha Koley, Anamika Jain, A.S. Thoke, Abhinav Jain, Detection and Classification of Faults on Six Phase Transmission Line using ANN", International Conference on Computer \& Communication Technology, Allahabad, India, (2011), 100 - 103.

22. A. Naresh Kumar, Chakravarthy, M, Fuzzy Inference System Based Distance Estimation Approach for Multi Location and Transforming Phase to Ground Faults in Six Phase Transmission Line, International Journal of Computational Intelligence Systems, 11, No. 1, (2018), 757-769. 